\title{
Energy Management Strategy Implementation for Hybrid Electric Vehicles Using Genetic Algorithm Tuned Pontryagin's Minimum Principle Controller
}

\author{
Aishwarya Panday and Hari Om Bansal \\ Department of Electrical and Electronics Engineering, Birla Institute of Technology and Science, Pilani, Jhunjhunu 333031, India \\ Correspondence should be addressed to Aishwarya Panday; aishwarya.panday@pilani.bits-pilani.ac.in
}

Received 31 October 2015; Accepted 11 January 2016

Academic Editor: Aboelmagd Noureldin

Copyright (C) 2016 A. Panday and H. O. Bansal. This is an open access article distributed under the Creative Commons Attribution License, which permits unrestricted use, distribution, and reproduction in any medium, provided the original work is properly cited.

\begin{abstract}
To reduce apace extraction of natural resources, to plummet the toxic emissions, and to increase the fuel economy for road transportation, hybrid vehicles are found to be promising. Hybrid vehicles use batteries and engine to propel the vehicle which minimizes dependence on liquid fuels. Battery is an important component of hybrid vehicles and is mainly characterized by its state of charge level. Here a modified state of charge estimation algorithm is applied, which includes not only coulomb counting but also open circuit voltage, weighting factor, and correction factor to track the run time state of charge efficiently. Further, presence of battery and engine together needs a prevailing power split scheme for their efficient utilization. In this paper, a fuel efficient energy management strategy for power-split hybrid electric vehicle using modified state of charge estimation method is developed. Here, the optimal values of various governing parameters are firstly computed with genetic algorithm and then fed to Pontryagin's minimum principle to decide the threshold power at which engine is turned on. This process makes the proposed method robust and provides better chance to improve the fuel efficiency. Engine efficient operating region is identified to operate vehicle in efficient regions and reduce fuel consumption.
\end{abstract}

\section{Introduction}

The invention of the automobile is one of the most groundbreaking advancements in technology. Today, it is impossible to imagine the world without it anymore. The automobile industry contributes significantly to the growth of the world's economy and affects each level of population. The present transportation structure heavily relies on internal combustion engine (ICE) based transportation, which uses fossil fuels as a source of energy. But due to toxic emissions of carbon dioxide $\left(\mathrm{CO}_{2}\right)$, carbon monoxide $(\mathrm{CO})$, nitrogen oxides $\left(\mathrm{NO}_{x}\right)$, and unburned hydrocarbons (HCs) in large amount, they have caused environmental pollution and global warming as well. Exponential rise in population and personal transportation resulted in multifold increase in automobiles around the globe. It has been causing severe environmental problems and a threat to human life. Air pollution is a major environmental jeopardy to health due to emissions of $\mathrm{CO}_{2}[1]$.
23 percent of total $\mathrm{CO}_{2}$ emissions in the world are caused by the transport sector [2], of which roughly 73 percent was generated by road transport [3]. In future oil production will fall, but its consumption will continue to rise so transport sector should eradicate dependence on oil by adapting the new transportation mediums like electric or hybrid vehicles which are green and sustainable. Hybrid vehicles are clean, efficient, and environment friendly transportation means. Hybrid electric vehicles (HEVs) use battery to store the electrical energy for propelling the vehicle with good fuel economy and less toxic emissions [4].

The presence of two power sources focuses on the need of designing an energy management strategy to split power between them to minimize the fuel consumption and maximize the power utilization. Complex structure of HEVs makes it challenging to design the control strategies. The preliminary objective of the control strategy is to satisfy the driver's power demand with minimum fuel consumption. 
TABLE 1: Comparison chart for real time optimization algorithms.

\begin{tabular}{llccc}
\hline Methods & \multicolumn{2}{c}{ Structural complexity } & Computation time Type of solution Requirement of a priori knowledge \\
\hline Particle swarm optimization & No & More & Global & No \\
Energy consumption minimization strategy & Yes & Small & Local & No \\
Pontryagin's minimum principle & No & Small & Local & Yes \\
Model predictive & No & Small & Global & No \\
Neural network & Yes & Small & Global & Yes \\
\hline
\end{tabular}

Moreover, fuel economy and emissions minimization are conflicting objectives; a smart control strategy should satisfy a trade-off between them.

In optimization based control strategies, the goal of a controller is to minimize the cost function. The cost function for an HEV may include the emission, fuel consumption, and torque, depending on the application. Global optimum solutions can be obtained by performing optimization over a fixed driving cycle. Due to causal nature of global optimization techniques, they are not suitable for real-time analysis. Therefore, global criterion is reduced to an instantaneous optimization, by introducing a cost function that depends only on the present state of the system parameters. Global optimization techniques do not consider variations of battery state of charge (SOC). Hence, a real-time optimization is performed for power split while maintaining the battery charge. The concept of real-time control strategy for efficiency and emission optimization of a parallel HEV is proposed in [5]. It considers all engine-motor torque pairs which forecast the energy consumption and emissions for every given point. An instantaneous fuel efficiency optimization strategy was developed for parallel hybrid vehicle with the charge sustaining mode in [6]. Also, to implement the global constraint, the authors developed a nonlinear penalty function in terms of battery SOC deviation from its desired value. Literature speaks that real-time optimization techniques like ECMS [6, 7], model predictive control (MPC) [8-10], Neural Network (NN) [11, 12], particle swarm optimization (PSO) [13-15], and Pontryagin's minimum principle (PMP) $[16,17]$ are used extensively. Table 1 compares different real-time strategies with its pros and cons. In the presence of a priori knowledge, PMP with structural simplicity and limited computation time gives local solution to the optimization problem which in case of particular assumption can provide the global optima [17].

Stockar et al. used PMP to build an optimal supervisory controller by reducing a global optimization problem into local. It reduces computational requirement and gives the freedom to solve the problem in the continuous time domain [18]. Stockar et al. proposed a model based control strategy to minimize the $\mathrm{CO}_{2}$ emission. A supervisory energy management strategy is implemented as a global optimization problem and then converted into local and, using PMP, optimal energy utilization for PHEVs is obtained. A real-time optimal control can be obtained using PMP as it uses instantaneous minimization of the Hamiltonian function [19]. Kim et al. state that solution based on PMP can be global optimal under some certain assumptions [20]. Kim et al. applied PMP based control strategies to the PHEVs and found that it gives a number of alternative solutions [21]. PMP provides a nearoptimal solution for optimal power management of HEVs if future driving conditions are known. It is suggested to find the proper costate, to keep SOC at a desired and predefined level.

In this paper PMP is applied to solve the performance index of the HEV in terms of fuel consumption. The requested power threshold is analyzed using PMP above which engine should be on, to work in its optimal efficient range, and generator can run to charge the battery to maintain the appropriate SOC level in the battery.

In HEVs, speed and power required by vehicle, SOC level, and engine off time play an important role to design energy management controller. PMP computes threshold power level, but initially designer needs to define the other parameters like optimal speed and torque ranges of engine, motor, and generator, highest and lowest level of SOC, target SOC, speed threshold, and engine off threshold to minimize the fuel consumption using vehicle controller. Optimal speed and torque ranges of engine, motor, and generator are defined by experiments done by the National Renewable Energy Laboratory (NREL) and provided in the package of Advanced Vehicle Simulator (ADVISOR) [22]. But speed threshold, engine off time threshold, and engine on SOC level are determined here using genetic algorithm (GA) which in turn, along with power threshold, decides engine on threshold.

GA is a heuristic search algorithm to solve optimization and search problems. This is a branch of artificial intelligence inspired by Darwin's theory of evolution. GA is a robust and feasible approach with a wide range of search space and rapidly optimizes the parameters using simple operations. They are proven to be effective to solve complex engineering optimization problems, characterized by nonlinear, multimodal, nonconvex objective functions. GA is efficient at searching the global optima, without getting stuck in local optima. Unlike the conventional gradient based method, GA does not require any strong assumption or additional information about objective parameters. GA can also explore the solution space very efficiently. Piccolo et al. utilize GA for energy management of an on road vehicle and minimize the cost function containing fuel consumption and emission [23]. Wang and Yang implemented a robust, easy, and real-time implementable FL based energy management strategy and used GA to tune and optimize the same [24]. To optimize the fuel consumption and emissions in a series HEV, GA based control strategy has been used by [25]. It is a flexible and global optimal multiobjective control strategy which is found 
to be better than thermostatic and divide rectangle (DIRECT) algorithm. Wimalendra et al. applied GA in parallel HEV to find the optimal power split for improved vehicle performance and also promises to give maximum fuel economy for known driving cycle for a parallel HEV using GA [26].

This paper aims to develop an optimal controller based on PMP and GA to get the optimal power split between engine and battery to fulfill the driver's speed and torque demand while compelling the engine to work in its efficient region. PMP is a powerful tool in optimal control theory which provides the set of necessary conditions to get the global solution of a constrained control problem.

The paper is divided into different sections. Section 2 explains the vehicle dynamics with vehicle model and planetary gear set operation. Section 3 explains power train control methodology involving engine speed control and traction torque control schemes. Section 4 elaborates problem statement, engine operating range description, and proposed control strategy. Section 5 discusses simulation and result discussion and Section 6 concludes the paper.

\section{Vehicle Dynamics}

The vehicle movement behavior depends upon different forces (aerodynamic drag, rolling resistance, and grading resistance) along its moving direction. Aerodynamic drag force is encountered by air in the direction of vehicle movement at a particular speed. Rolling resistance is a horizontal force which acts on the wheel center in the opposite movement direction of the wheel. Grade force acts on the vehicle either in opposite or in the same direction when a vehicle goes up or down over a slope:

$$
F_{r}=\frac{1}{2} \rho A_{f} C_{D}\left(V-V_{W}\right)^{2}+P f_{r}+M g \sin \alpha,
$$

where $A_{f}$ is vehicle frontal area, $C_{D}$ is aerodynamic drag that characterizes the shape of the vehicle body, $\rho$ is air density, $V$ is vehicle speed and $V_{W}$ is component of wind speed with vehicle moving direction, $P$ is force acting on the center of a standstill tire, $f_{r}$ is rolling resistance, and $\alpha$ is road angle.

Figure 1 shows the main components of the HEVs, that is, motor, generator, battery, and engine [4]. Presence of the engine and battery together in vehicle demands for coupler to add their speeds. In Toyota hybrid system (THS), planetary gear system (PGS) is used as a speed coupler. PGS contains carrier, sun, ring gear, and several pinion gears as shown in Figure 2. The ring gear is attached to the motor and final drive, engine to the carrier, and generator to the sun. Governing equations between different gear speeds and radii are given as follows:

$$
\omega_{r} * r_{r}=-\omega_{s} * r_{s}+\omega_{c}\left(r_{s}+r_{r}\right),
$$

where $\omega_{r}, \omega_{s}$, and $\omega_{c}$ are ring, sun, and carrier angular speeds, respectively, and $r_{r}, r_{s}$ are ring and sun radii, respectively. Neglecting energy losses in steady state operation and torques

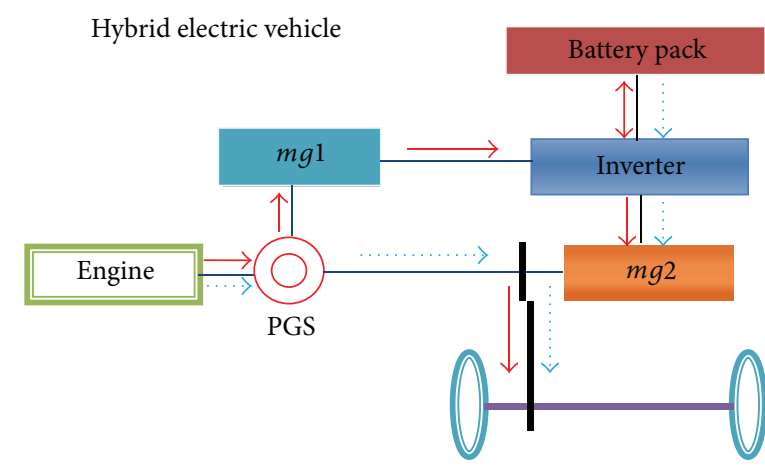

$\cdots$ Power flow along parallel paths
$\longrightarrow$ Power flow along series paths

FIgure 1: Power split hybrid architecture.

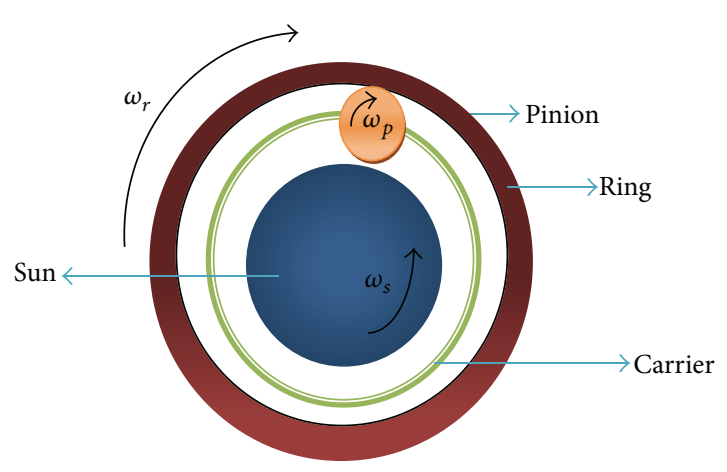

FIGURE 2: Operation of a planetary gear.

acting on sun, ring, and carrier have the relationship as follows:

$$
T_{c}=-k_{y s} T_{s}=-k_{y r} T_{r},
$$

$T_{c}, T_{s}$, and $T_{r}$ are the torques acting on carrier, sun, and ring gear, $k_{y r}=\left(1+i_{g}\right) / i_{g}$ and $k_{y s}=\left(1+i_{g}\right)$, and $i_{g}$ is gear ratio. While moving, engine speed $\omega_{e}$, motor speed $\omega_{m}$, and generator speed $\omega_{g}$ are related as follows:

$$
\frac{N_{r}}{N_{s}+N_{r}} * \omega_{m}+\frac{N_{s}}{N_{s}+N_{r}} * \omega_{g}=\omega_{e}
$$

where $N_{r}$ and $N_{s}$ are tooth number in ring and sun gear, respectively, in Toyota Prius. As $N_{r}=78$ and $N_{s}=30$, (2) becomes

$$
7.2222 * \omega_{m}+0.2778 * \omega_{g}=\omega_{e} .
$$

This equation describes that $\omega_{m}$ is directly proportional to the linear speed of the vehicle with a quantitative change due to tire radius and final drive ratio.

2.1. Battery Modeling and SOC Estimation. In general, classical SOC estimation is performed using ampere hour counting method (in ADVISOR also), but open circuit voltage 


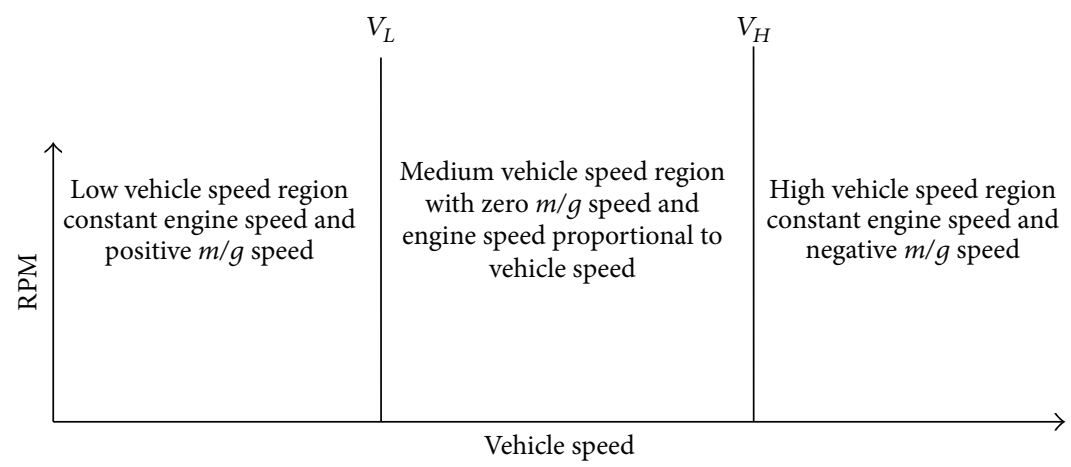

FIGURE 3: Various vehicle speed ranges.

(OCV) also plays an important role in determining the SOC. Tang et al. [27] and Verbrugge and Tate [28] identified the contribution of both coulomb counting method $\left(\mathrm{SOC}_{i}\right)$ and open circuit voltage method $\left(\mathrm{SOC}_{V}\right)$ together to estimate the accurate SOC. References [29-31] have also identified the importance of $\mathrm{SOC}_{V}$ and $\mathrm{SOC}_{i}$ in calculating the run-time SOC. The SOC estimation formula proposed by the authors is given as follows:

$$
\mathrm{SOC}=w \mathrm{SOC}_{V}+(1-w)\left(\mathrm{SOC}_{i}-\eta\right)
$$

where $\eta$ is correction factor (CF). CF varies with the changing SOC, load $L$, and temperature $T$ (i.e., $\mathrm{CF}=f\left(\mathrm{SOC}_{0}, L, T\right)$ ) and can be formulated as in (7):

$$
\begin{aligned}
& \eta_{298}=\left(1-\frac{\mathrm{SOC}_{0}}{100}\right), \quad L=0 \text { at } T=298 \mathrm{~K}, \\
& \eta_{\text {new }(\mathrm{SOC}, T)}=\eta_{298}+\frac{(\mathrm{SOC} / 1000)}{T-298} \pm \varepsilon, \\
& L>0 \text { at any } T .
\end{aligned}
$$

Estimating SOC by (7) and (8) will promise a better fuel efficiency of HEV as accuracy of SOC estimation is improved.

Battery plays a vital role in HEVs. In most of the literature, energy management techniques for HEVs have used batteries with a single $R_{\text {int }}$ component which consists of ohmic and polarization resistances. But, due to double-layer formation at the electrode/solution interface, capacitive effects arise [32]. This capacitance consists of purely electrical polarization capacitance and diffusion capacitance [33]. The transient response of the battery is highly influenced by double-layer and diffusion capacitance when the rates of reactions are high. This effect can be modeled using lumped capacitances in parallel with the resistances [34]. Inclusion of diffusion and double-layer resistances and capacitances ( $R$ and $C$ components) will lead to the accurate SOC estimation. In this paper, to predict the run-time behavior of the battery, $1 \mathrm{RC}$ and $2 \mathrm{RC}$ models along with modified SOC estimation techniques are used to analyze the effect on fuel efficiency.
Rate of change of SOC depends on $P_{-}$bat, open circuit voltage (OCV), and resistance $R$ offered by the battery cells and capacity $Q_{p}$ shown in

$$
\mathrm{SOCC}=\frac{\mathrm{OCV}-\sqrt{\mathrm{OCV}^{2}-4 * R * P \_ \text {bat }}}{2 * R * Q_{p}} .
$$

Required power of $P$ bat can be calculated as follows:

$$
P_{\text {bat }}=\eta_{c 1}^{k} T_{m g 1} \omega_{m g 1}+\eta_{c 2}^{k} T_{m g 2} \omega_{m g 2} \text {, }
$$

where $\eta_{c 1}^{k}$ and $\eta_{c 2}^{k}$ are the efficiencies of $m g 1$ and $m g 2$, respectively, and are obtained from the efficiency map of $m g s$. Positive $k$ represents motoring operation and negative $k$ represents generating operations. Equations (6), (8), and (9) are applicable for different battery models proposed in the literature.

\section{Powertrain Control Methodology}

Power split HEVs have the potential to improve in fuel efficiency compared to series or parallel hybrids because engine speed and torque can be decoupled completely or partially from the driven wheels through speed and torque coupling. By applying suitable control strategies fuel efficiency can be improved provided it follows the control objectives, like (1) driver torque and speed demand are fulfilled, (2) engine operates in its best efficiency region, (3) target SOC level meets at the end of the trip, and (4) maximum braking energy is recuperated while braking or decelerating. While making the control strategies, different approaches can be followed as elaborated below.

3.1. Engine Speed Control Strategy. Vehicle speed ranges are divided into three regions, namely, (1) low, (2) medium, and (3) high vehicle speed, as shown in Figure 3. In low speed region motor fulfills the driver power demand and hence engine usage can be avoided which is inefficient also. Low vehicle speed, $V_{L}$, threshold can be decided by the lowest engine speed allowed with zero motor/generator speed as follows:

$$
V_{L}=\frac{\pi k_{y r} n_{e_{-} \min } r_{w}}{30 i_{r w}}(\mathrm{~m} / \mathrm{s}),
$$


where $n_{e \_ \text {min }}$ is the minimum engine speed allowed, $r_{w}$ is the wheel radius, $k_{y r}=\left(1+i_{g}\right) / i_{g}$, where $i_{g}$ is the gear ratio and is defined as $r_{r} / r_{s}$ and $i_{r w}$ is the gear ratio of the ring gear to drive train wheels. In this region motor/generator operates with a positive speed $n_{m / g}$ as follows:

$$
n_{m / g}=k_{y s}\left(n_{e \_ \text {min }}-\frac{30 i_{r w} V}{\pi k_{y r} r_{w}}\right)
$$

$V$ is the vehicle speed in $\mathrm{m} / \mathrm{s}\left(V \leq V_{L}\right)$. From (3) torque produced by motor/generator, applied to the sun gear, has direction opposite to its speed. Therefore, motor/generator absorbs part of the engine power to charge the battery. Power on the motor/generator shaft $P_{\mathrm{m} / \mathrm{g}}$ can be expressed as (12). $T_{\mathrm{m} / \mathrm{g}}$ is torque produced by motor/generator.

$$
P_{m / g}=\frac{2 \pi}{60} T_{m / g} n_{m / g}=\frac{2 \pi}{60} T_{e} n_{e \_ \text {min }}-\frac{i_{r w}}{k_{y r} r_{w}} T_{e} V .
$$

When the vehicle speed is higher than $V_{L}$ but lower than $V_{H}$ given by (13), motor/generator is deenergized and sun gear is locked to the stationary frame of the vehicle. Drive train operates in torque coupling mode. Engine speed is proportional to the vehicle speed. Consider

$$
V_{H}=\frac{\pi k_{y r} n_{e \_ \text {max }} r_{w}}{30 i_{r w}}(\mathrm{~m} / \mathrm{s})
$$

where $n_{e_{\text {max }}}$ is the maximum engine RPM allowed. In this medium speed region all the engine power is delivered to the wheels.

When the vehicle speed is higher than the $V_{H}$, for limiting the engine speed below the maximum engine allowed speed $n_{\text {e_max }}$, motor/generator has to operate in the direction opposite to the engine speed. It can be expressed as follows:

$$
n_{m / g}=k_{y s}\left(n_{e \_ \text {max }}-\frac{30 k_{y s} i_{r w} V}{\pi k_{y r} r_{w}}\right) \text {, }
$$

where $V \geq V_{H}$. The motor generator is in motoring mode, and motoring power can be expressed as follows:

$$
\begin{aligned}
P_{m / g} & =\frac{2 \pi}{60} T_{m / g} n_{m / g} \\
& =\frac{i_{r w}}{k_{y r} r_{w}} T_{e} V-\frac{2 \pi}{60} \frac{i_{r w}}{k_{y r} r_{w}} T_{e} n_{e \_ \text {max }} .
\end{aligned}
$$

3.2. Traction Torque Control Strategy. In low vehicle speed region when sufficient $S O C$ is available traction motor torque $T_{m t}$ can be given as follows:

$$
\begin{aligned}
T_{m t} & =\frac{60}{2 \pi} \frac{P_{m / g}}{n_{t m}}=\left(\frac{n_{e \_ \text {min }}}{n_{t m}}-\frac{i_{r w}}{k_{y r} i_{m w}}\right) T_{e} \\
& =-\left(\frac{2 \pi r_{w}}{60 i_{m w}} \frac{n_{e \_m i n}}{V}-\frac{i_{r w}}{k_{y r} i_{m w}}\right) T_{e},
\end{aligned}
$$

where $i_{m w}$ is gear ratio from the traction motor to the driven wheels and $n_{t m}$ is traction motor speed. PGS, $\mathrm{m} / \mathrm{g}$, and traction motor together function as an EVT, because no energy goes into or out of the battery.

In case of medium vehicle speed range only the torque coupling mode is employed; that is, sun gear is locked to the vehicle stationary frame and engine speed is proportional to the vehicle speed. In high speed region engine speed is controlled by the engine max speed $n_{e \_ \text {max }}$ and the motor/generator works in motoring mode. If the commanded traction torque is higher than the torque that the engine can produce with its optimal throttle at the speed of $n_{e-\max }$ and SOC of the battery is lower than $\mathrm{SOC}_{\min }$ and the battery cannot be discharged any more to support motoring mode, the engine will be forced to operate at the higher speed (beyond the optimal range) to fulfill the driver power demand. In this case, engine alone mode can be used with torque coupling or engine can run at somewhat higher speed so that a motor/ generator can work in generating mode to feed the traction motor to support engine by providing additional torque. For the latter case, $n_{e}$ can be calculated as in (17):

$$
n_{e}>\frac{30 i_{r w} V}{\pi k_{y r} r_{w}}
$$

If SOC is higher than the $\mathrm{SOC}_{\min }$, then the engine should be controlled at its $n_{e_{\text {_max }}}$ with optimal throttle and traction motor provides additional torque to engine to support the driver torque demand.

If the commanded traction torque is smaller than the engine torque and SOC is lower than $\mathrm{SOC}_{\text {min }}$, engine is operated according to (13) and traction motor works in generating mode. If SOC is in between range of $\mathrm{SOC}_{\min }$ and $\mathrm{SOC}_{\max }$, traction motor may be de-energized and engine alone mode can be projected. If SOC is greater than the $\mathrm{SOC}_{\max }$, engine better shuts down and traction motor alone can propel the vehicle.

\section{Proposed Energy Management Approach}

In HEVs, presence of both motor and engine together makes it inevitable to decide engine/motor on/off condition to minimize the fuel consumption. To split the power optimally between two power sources, a cost function is derived. The cost function depends on various parameters like speed, power, SOC, and engine on/off time. The various steps involved in developing the strategy are given below.

4.1. Problem Statement. The proposed cost function involves rate of fuel consumption; that is, $J=\dot{m}_{f t}$, where $\dot{m}_{f t}$ is total fuel consumption in a driving cycle. $\dot{m}_{f}$ is the time rate of fuel consumption and is given by $\dot{m}_{f}=\left(\left(P_{e} * g_{e}\right) /\left(1000 * \gamma_{f}\right)\right)(l / h)$ where $P_{e}$ is engine power, $g_{e}$ is specific fuel consumption, and $\gamma_{f}$ is mass density of fuel, $\mathrm{kg} / \mathrm{L}$. So total fuel consumption in a driving cycle is $\dot{m}_{f t}=\sum\left(P_{e} g_{e} / 1000 \gamma_{f}\right) * \Delta t_{i}$. The cost function 
TABLE 2: Vehicle components and drive cycle specifications.

\begin{tabular}{lccc}
\hline \multicolumn{2}{c}{$\begin{array}{c}\text { Vehicle component specification } \\
\text { (Toyota Prius) }\end{array}$} & & Drive cycle specification (ECE_EUDC) \\
Components & Values & Entities & $74.56 \mathrm{mph}$ \\
\hline Motor & $31 \mathrm{~kW}$ & Maximum speed & $19.95 \mathrm{mph}$ \\
Engine & $43 \mathrm{~kW}$ & Average speed & $3.46 \mathrm{ft} / \mathrm{s}^{2}$ \\
Heating value of gasoline & $42600 \mathrm{~J} / \mathrm{g}$ & Maximum acceleration & $-4.56 \mathrm{ft} / \mathrm{s}^{2}$ \\
$Q_{\mathrm{HV}}$ & $15 \mathrm{~kW}$ & Maximum deceleration & 13 \\
Generator & 0.3 & No of stops \\
Drag coefficient & $40 \mathrm{~kW}$ & Distance & $6.79 \mathrm{miles}$ \\
Battery & 3.93 & Time & $1225 \mathrm{~s}$ \\
Final drive ratio & $1.746 \mathrm{~m}^{2}$ & \\
Frontal area & $0.287 \mathrm{~m}$ & \\
Wheel radius & $918 \mathrm{~kg}$ & & \\
Vehicle glider mass & & & \\
\hline
\end{tabular}

is minimized over ECE_EUDC driving cycle subject to the following constraints:

$$
\begin{gathered}
\omega_{e, \min } \leq \omega_{e} \leq \omega_{e, \max }, \\
\omega_{m g 1, \min } \leq \omega_{m g 1} \leq \omega_{m g 1, \max }, \\
\omega_{m g 2, \min } \leq \omega_{m g 2} \leq \omega_{m g 2, \max }, \\
T_{e, \min } \leq T_{e} \leq T_{e, \max }, \\
T_{m g 1, \min } \leq T_{m g 1} \leq T_{m g 1, \max }, \\
T_{m g 2, \min } \leq T_{m g 2} \leq T_{m g 2, \max }, \\
\mathrm{SOC}_{\min } \leq \mathrm{SOC} \leq \mathrm{SOC}_{\max },
\end{gathered}
$$

where $\omega_{e, \min }, \omega_{e, \max }, \omega_{m g 1, \min }, \omega_{m g 1, \max }, \omega_{m g 2, \min }, \omega_{m g 2, \max }$, $T_{e, \text { min }}, T_{e, \text { max }}, T_{m g 1, \max }, T_{m g 1, \min }, T_{m g 2, \min }, T_{m g 2, \max }, \mathrm{SOC}_{\min }$, and $\mathrm{SOC}_{\max }$ are the minimum and maximum values of speed and torque considered as constraints range of engine, $m g 1$, $m g 2$, and SOC, respectively.

Torques and speeds of $m g 1$ and $m g 2$ are functions of engine torque and speed, requested driving speed and torque, and gear ratios of the vehicle as follows:

$$
\begin{aligned}
& T_{m g 1}=-\frac{1}{1+R}\left[T_{e}\right], \\
& \omega_{m g 1}=-R \zeta \omega_{\text {req }}+(1+R) \omega_{e}, \\
& T_{m g 2}=-\frac{1}{(1+R)}\left[-\frac{(1+R) T_{\text {req }}}{\zeta}+R T_{e}\right], \\
& \omega_{m g 2}=\zeta \omega_{\text {req }}
\end{aligned}
$$

where $\omega_{m g 1}, T_{m g 1}, \omega_{m g 2}, T_{m g 2}, \omega_{e}$, and $T_{e}$ are speeds and torques $m g 1, m g 2$, engine, respectively, and $\omega_{\text {req }}$ and $T_{\text {req }}$ are the requested speed and torque. $R$ and $\zeta$ are the gear ratio of PGS and the final drive ratio $[35,36]$. As efficiency of an engine is a function of engine speed $\omega_{e}$ and torque $T_{e}$, fuel consumption will be $\dot{m}_{f}=f\left(\omega_{e}, T_{e}\right)$.
Power requested should always be delivered by either motor, engine, or generator; that is, for the successful trip completion $P_{\text {requested }}=P_{\text {delivered }}=P_{\text {engine }}+P_{\text {motor }}+P_{\text {generator }}$.

Speed, force, and torque requested by ECE_EUDC shown in Figure 4 are used to calculate power required at the wheel. Positive force/torque value shows that power is required to propel the vehicle and negative force/torque specifies that the energy will be released and regenerative braking will be applied to recuperate the released energy in the battery. Vehicle component's and drive cycle specification are given in Table 2.

4.2. Determination of Efficient Operating Region of Engine. It is mandatory to identify engine's fuel efficient regions before finding the optimal solution of the cost function. The energy management controller should keep the engine in its efficient region to minimize the liquid fuel consumption. Fuel consumption is a measure of the mass flow per unit time. Fuel flow rate per useful power output is an important parameter to determine the efficiency of the engine and is called specific fuel consumption (SFC); that is, $s f c=\dot{m}_{f} / P$. When the engine power is measured as the net power from the crankshaft, SFC is called brake specific fuel consumption (BSFC). Low values of SFC or BSFC are always desirable. The ratio of work produced to the amount of fuel energy supplied per cycle is measure of engine efficiency (fuel conversion efficiency). $\eta_{f}=W_{c} / m_{f} Q_{\mathrm{HV}}=P / \dot{m}_{f} Q_{\mathrm{HV}}$, where $W_{c}$ is work done in one cycle, $m_{f}$ is fuel mass consumed per cycle, and $Q_{H V}$ is the heating value of the fuel. The efficiency can be expressed as $\eta_{f}=1 /\left(s f c * Q_{\mathrm{HV}}\right)$. Engine characteristics are decided by parameters like power, torque, mean effective pressure, SFC, indicated, brake power and torque, and fuel consumption characteristics.

Fuel efficient region of the engine is mainly governed by requesting power at the ring gear of PSG and maximum and minimum speeds of generator and vehicle idle speed. Based on power demand, optimal $\omega_{e}^{*}$ and $T_{e}^{*}$ points are determined. $\omega_{e}$ is controlled with generator torque; that is, generator torque is so adjusted that engine runs at desired speed. Engine 


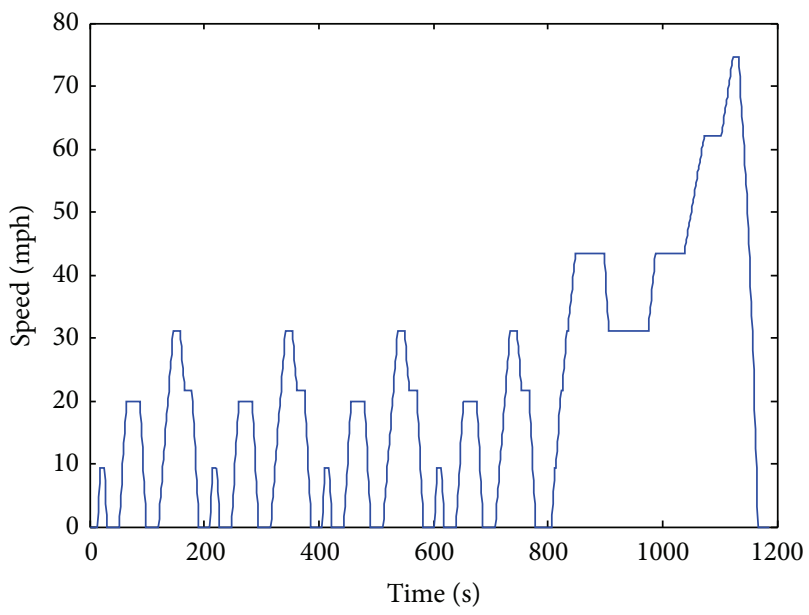

(a)
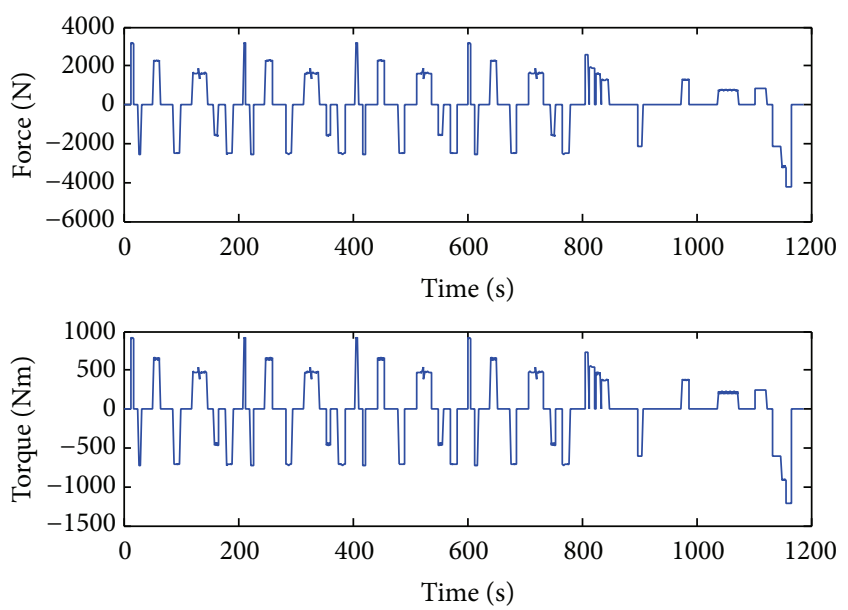

(b)

FIGURE 4: ECE_EUDC driving cycle: (a) speed required, (b) force and torque required.

maximum $\left(\omega_{e_{-} \max }\right)$ and minimum $\left(\omega_{e_{-} \min }\right)$ speed are ranged using the following equation:

$$
\begin{aligned}
& \frac{N_{r}}{N_{s}+N_{r}} * \omega_{\text {ring }}+\frac{N_{s}}{N_{s}+N_{r}} * \omega_{g_{\max }}=\omega_{e_{-} \max }, \\
& \frac{N_{r}}{N_{s}+N_{r}} * \omega_{\text {ring }}+\frac{N_{s}}{N_{s}+N_{r}} * \omega_{g_{\min }}=\omega_{e_{-} \min },
\end{aligned}
$$

where $\omega_{\text {ring }}$ is the speed requested at ring gear. The engine fuel efficiency map is shown in Figure 5 which infers that, below a certain speed, torque produced by the engine is less hence not efficient. ICE is rated at a specific RPM level for maximum torque and maximum power. ICE cannot produce effective torque below "some" certain speed. Maximum torque is achieved for a narrow range of speeds beyond which efficiency decreases. The characteristic of the engine is shown in Figure 6. This characteristic shows that engine's actual horsepower is lower than the ideal lab conditions further below

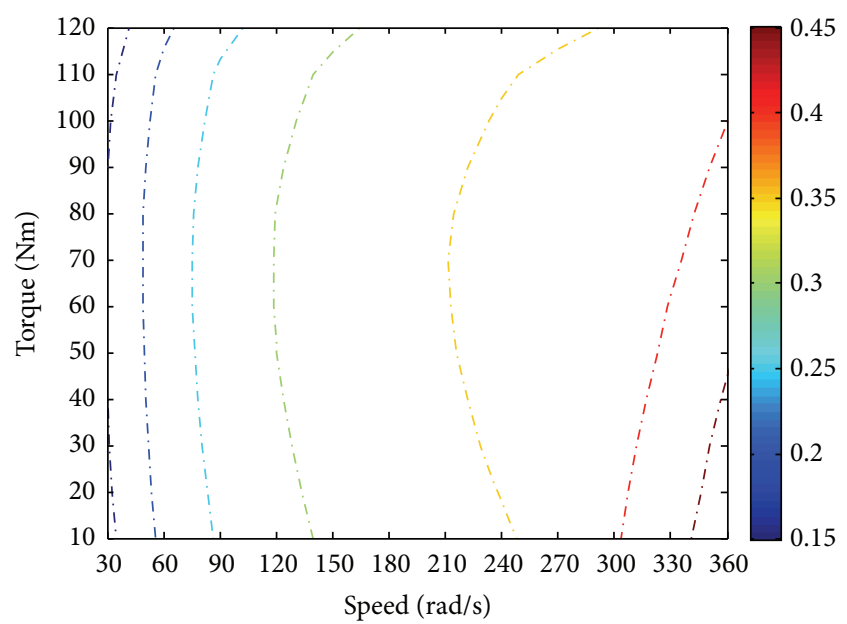

Figure 5: Engine efficiency map of Toyota Prius.

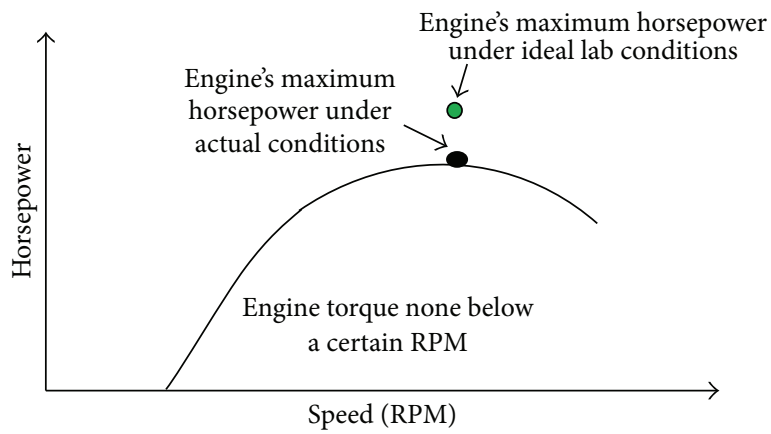

FIGURE 6: Generalized engine speed-torque characteristics.

a certain speed, and no positive torque is achieved. For the considered engine model, maximum power of $43 \mathrm{kw}$ and maximum torque of $101 \mathrm{~N}-\mathrm{m}$ are provided by engine at 4000 RPM. So, it is required to operate the engine in its most efficient region for the better performance and lesser fuel consumption.

4.3. Optimization Strategies. The proposed fuel efficiency optimization problem depends on various parameters of the vehicle. These parameters may have cross effects also. The proposed method uses, firstly, GA to identify optimal values of various governing parameters and then these values are fitted into PMP to produce optimum fuel efficiency.

4.3.1. Genetic Algorithm. To optimize a nonlinear problem using GA, chosen parameters will not be treated as independent variables. The combined effect of these parameters reflects on optimized output. Genetic algorithm was devised by John Holland in early 1970's to imitate natural properties based on natural evolution. To obtain the solution of a problem, the algorithm is started with a set of solutions known as population. A new population is formed by choosing random solutions of one population and is assumed that new 


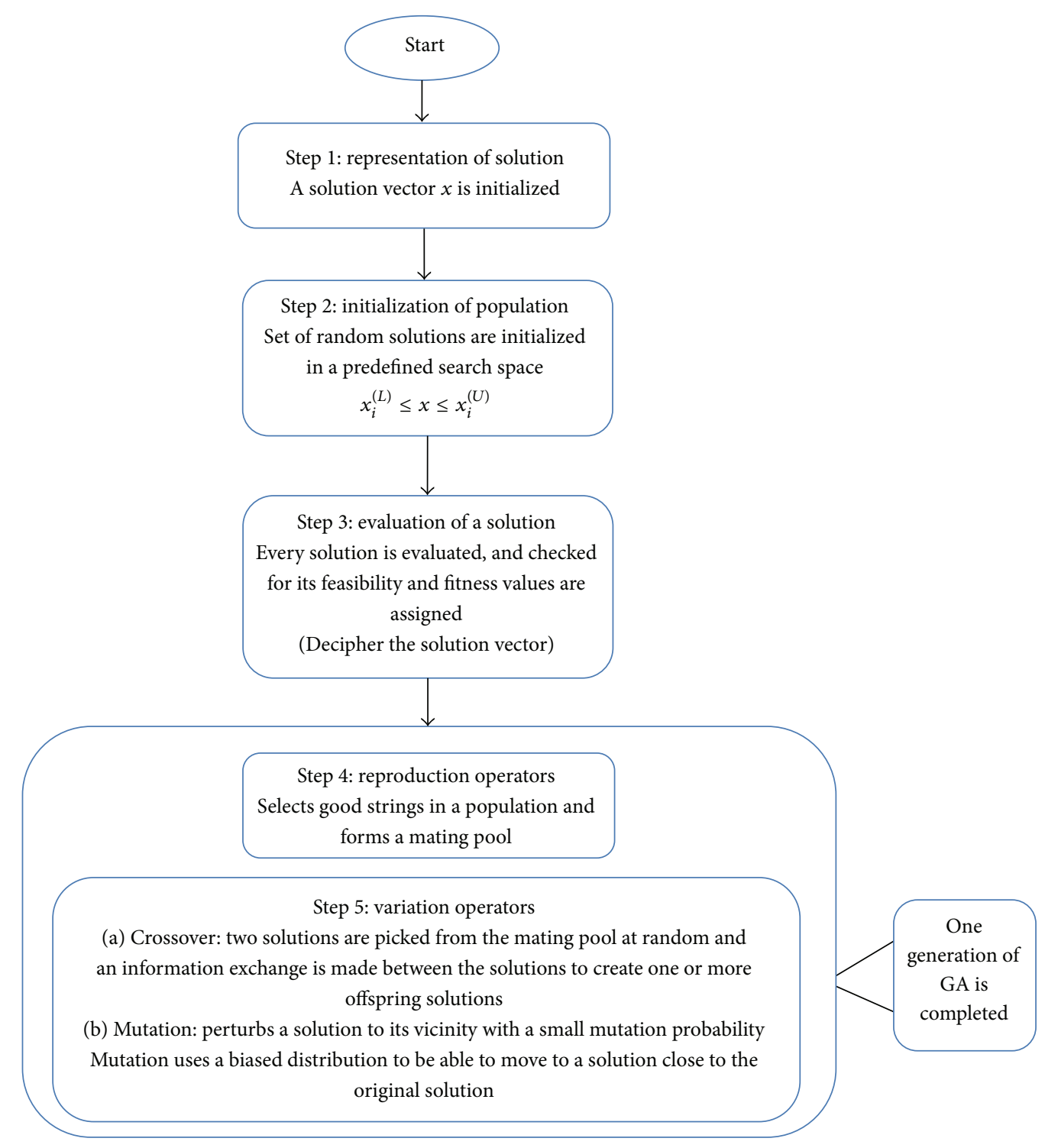

FIGURE 7: Genetic algorithm process flow.

population is better than the old one. This course is repeated over numerous iterations or until some termination criteria is satisfied [37, 38]. The flow of the algorithm is shown in Figure 7.

4.3.2. Pontryagin's Minimum Principle. PMP was proposed by Russian mathematician Lev Semenovich in 1956. It gives the best possible control to take a dynamical system from one state to another in the presence of constraints for some state or input control. PMP is a special case of Euler-Lagrange equation of calculus of variations. For an optimum solution, PMP provides only necessary conditions and the sufficient conditions are satisfied by Hamilton-Jacobi-Bellman equation. In PMP, the number of nonlinear second-order differential equations linearly increases with dimension so the control based on PMP takes less computational time for getting an optimal trajectory but it could be a local optimal, not a global solution. Trajectory obtained by PMP could be considered a global optimal trajectory under certain assumptions. These are as follows: (1) trajectory obtained from PMP is unique and satisfies the necessary and boundary conditions, (2) some geometrical properties of the optimal field provide the possibility of optimality clarification, and (3) as a general statement of the second approach the absolute optimality is, mathematically, proven by clear proposition [17, 39].

To optimize any problem using PMP, the Hamiltonian is formed first and then minimized with respect to control input. Then state and costate equations are obtained by following the set procedure. The flow diagram can be corrugated as in Figure 8.

For performance measure of the form $J=S(x(t), u(t), t)+$ $\int_{t_{0}}^{t_{f}} V(x(t), u(t), t)$ with the terminal cost $S(x(t), u(t), t)$, instantaneous cost $\int_{t_{0}}^{t_{f}} V(x(t), u(t), t)$, and the state equation 


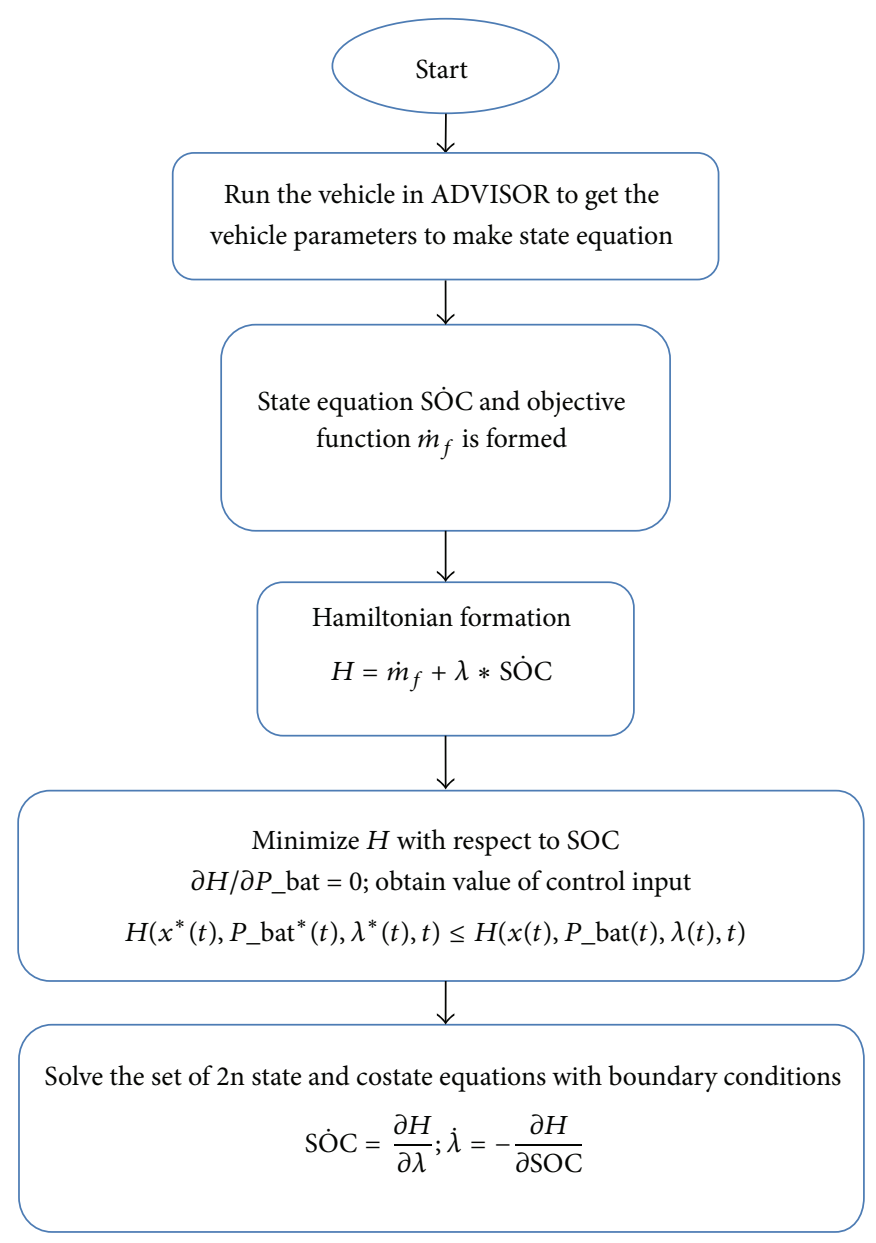

FIgURE 8: PMP process flow.

of the form $x(t)=f(x(t), u(t), t)$, Hamiltonian constructions involve instantaneous cost and state equation with a time varying vector multiplier $\lambda$ as follows:

$$
\begin{aligned}
H & (x(t), u(t), \lambda(t), t) \\
& =V(x(t), u(t), t)+\lambda^{T}(t) * \dot{x}(t) .
\end{aligned}
$$

According to PMP, optimal control trajectory $u^{*}(t)$, optimal state trajectory $x^{*}(t)$, and corresponding optimal costate trajectory $\lambda^{*}(t)$ minimize the Hamiltonian such that

$$
\begin{aligned}
& H\left(x^{*}(t), u^{*}(t), \lambda^{*}(t), t\right) \\
& \quad \leq H(x(t), u(t), \lambda(t), t) .
\end{aligned}
$$

The following relations and constraints (23) must hold with the above condition:

$$
\begin{aligned}
& \dot{x}^{*}(t)=\frac{\partial H}{\partial \lambda}\left(x^{*}(t), u^{*}(t), \lambda^{*}(t), t\right), \\
& \dot{\lambda}^{*}(t)=-\frac{\partial H}{\partial x}\left(x^{*}(t), u^{*}(t), \lambda^{*}(t), t\right) .
\end{aligned}
$$

Initial conditions $x_{0}$ and final condition $\left[H^{*}+\partial S / \partial x\right]_{t_{f}} \partial t_{f}+$ $\left[(\partial S / \partial x)_{*}-\lambda^{*}(t)\right]_{t_{f}}^{\prime} \delta x_{f}$ both are assumed to be zero.

If PMP conditions are satisfied, the solution will be extrenal and if a global solution exists, it will be the global solution.

\section{Strategy Analysis, Simulation, and Result Discussion}

The engine in its efficient operating range and motor with sufficient SOC will lead to fuel efficient strategy. Speed, power, SOC, and engine on/off time are the deciding factors and their threshold values must be determined to run an HEV with maximum fuel efficiency.

GA first finds optimal values of engine on SOC, speed, and engine off time (cs_min_off_time, cs_eng_on_soc, cs_electric_launch_spd, and cs_eng_min_spd) thresholds while fulfilling the driver demand; that is, requested trace (road map) should meet at each instant of time over a road trip. Improper values of these parameters will reduce the fuel efficiency. After selecting threshold values of vehicular parameters using 
TABLE 3: Fuel economy comparison for different battery models.

\begin{tabular}{lcccc}
\hline \multirow{2}{*}{ Battery model } & \multicolumn{3}{c}{ Fuel economy (mpgge) } & Trace analysis \\
& With GA & Without GA & Percentage improvement & With trace miss \\
\hline$R_{\text {int }}$ conventional model & 55.9208 & 44.9785 & 24.3278 & No trace miss \\
$R_{\text {int }}$ model $^{*}$ & 60.6184 & 51.0401 & 18.7662 & No trace miss \\
1 RC model $^{*}$ & 60.6250 & 51.3732 & 18.00 & No trace miss \\
2 RC model & 60.5423 & 51.1247 & 18.428 & \\
\hline
\end{tabular}

${ }^{*}$ With modified SOC estimation method.

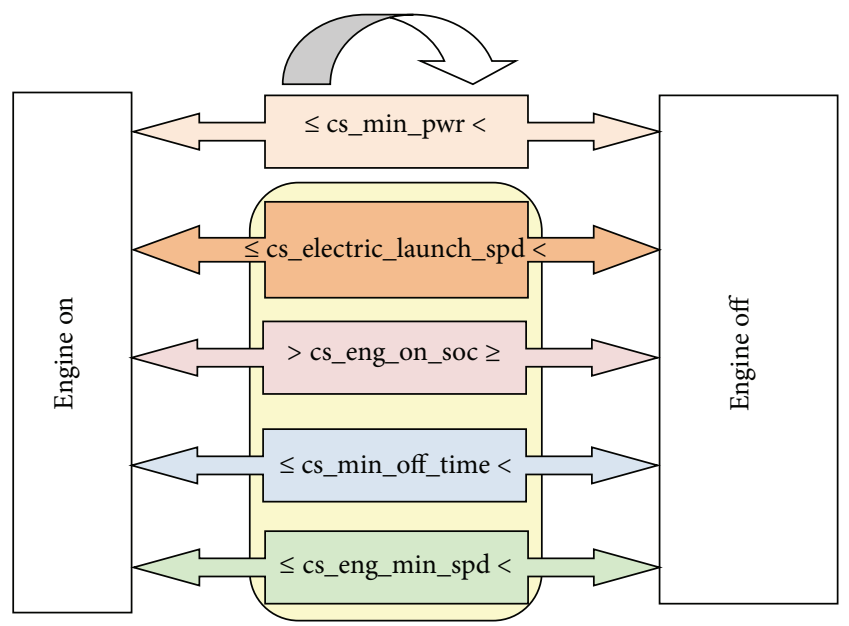

FIGURE 9: Engine on/off decision.

GA, they are now fed to PMP which finally reckons threshold power to turn the engine on. The effect of this hybrid control strategy is visible in terms of improved efficiency as shown in Table 3. Four different cases are analyzed here: (1) $R_{\text {int }}$ battery model with conventional SOC estimation used in ADVISOR and (2) $R_{\text {int }}$, (3) $1 \mathrm{RC}$, and (4) 2 RC battery models with modified SOC estimation method $[29,31]$. A considerable improvement is observed in fuel efficiency using modified SOC estimation method over conventional. Models with modified SOC estimation give 8-9 percent improvement over conventional methods. Modified SOC estimation method with $R_{\text {int }}, 1 \mathrm{RC}$, and $2 \mathrm{RC}$ models do not make much difference in efficiencies as their OCVs, resistances, and capacity variations are close to each other. To take care of the actual battery behavior one should consider $R$ and $C$ components instead of $R_{\text {int }}$ only in HEV analysis. One RC battery model is used here further to avoid the complexity of $2 \mathrm{RC}$ models. Figure 9 provides required conditions to turn the engine on/ off. Here, cs_min_pwr decides minimum power commanded of the engine; below this engine should be principally shut off. cs_electric_launch_spd is a vehicle speed threshold below which engine will be off. cs_min_off time is the shortest allowed duration of the engine off period; after this time has passed, the engine may restart if high power is requested. Below cs_eng_on_soc value, the engine must be on. Below cs_eng_min_spd, fuel can be cut; that is, engine does not use fuel.

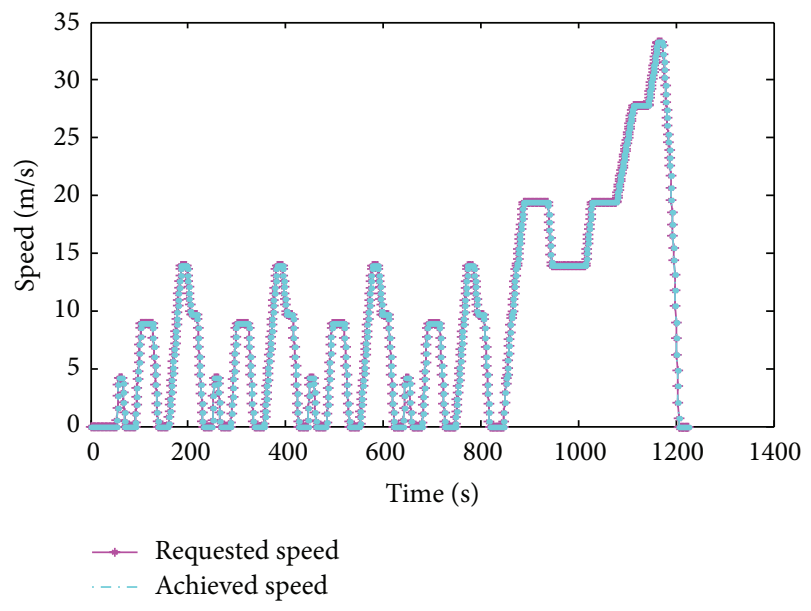

FIGURE 10: Vehicle requested and delivered speed comparison.

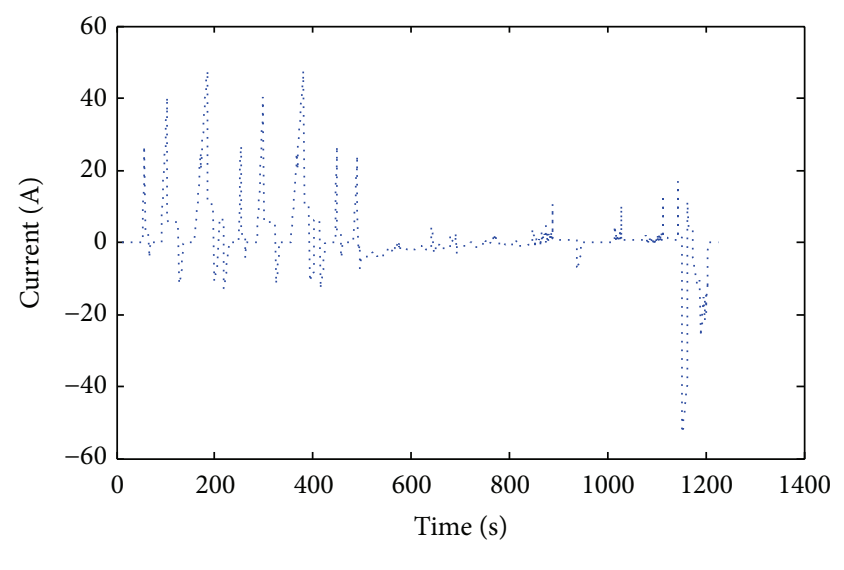

Battery current

FIGURE 11: Battery current over the trip.

To verify the correctness of proposed strategy, requested speed and delivered speed of the vehicle are compared and shown in Figure 10. The figure infers that these two match perfectly and there is no trace miss. Vehicle requested power is fulfilled by different components alone or together. Figure 4(b) signifies the time instances of negative torque; that is, kinetic energy $\left(=1 / 2 \mathrm{MV}^{2}\right)$ stored in vehicles translating mass can be stored during these moments, if the deceleration rate is greater than $10 \mathrm{~km} / \mathrm{h}$. The traction motor operates as generator to recuperates the energy and charges battery as shown in Figure 11. Positive current flow delivers 


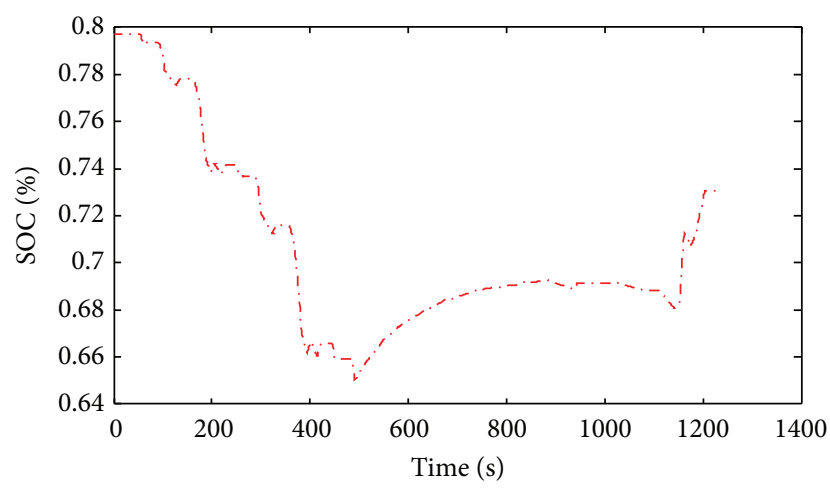

...- SOC variation

(a)

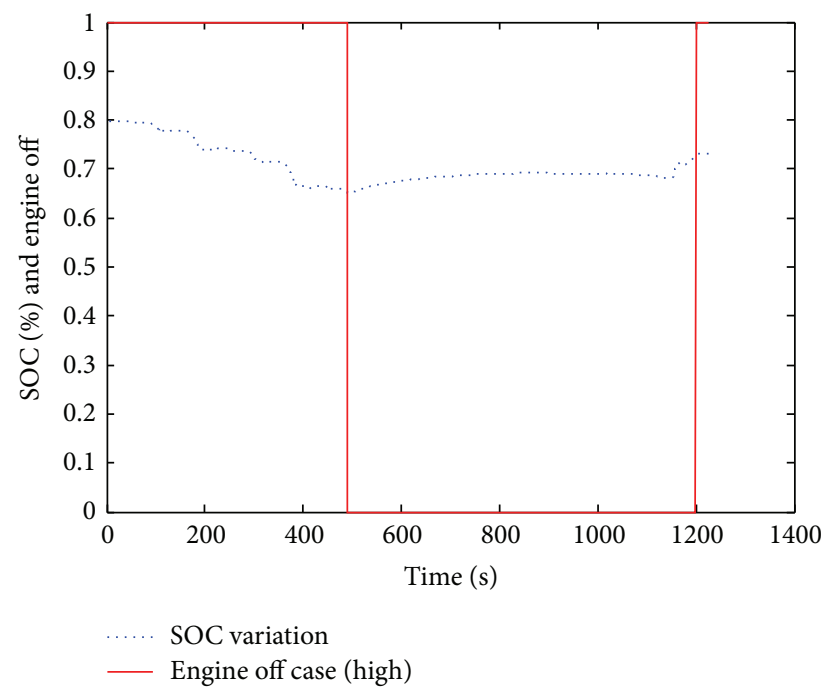

(b)

FIGURE 12: SOC status: (a) SOC variation over the trip and (b) SOC variation with engine on/off condition.

the current from the battery and negative current signifies the condition of battery getting charged.

Battery SOC variation over the trip and with engine on/off is shown in Figure 12 at $25^{\circ} \mathrm{C}$ with initial SOC as 80 and target as 70 percent. Figure 13 shows the motor and engine efficiency points and promise to work in most efficient range possible while acquiring the trace and maintaining SOC.

\section{Conclusion}

In this paper, a modified SOC estimation method is used to track the run-time SOC of the batteries and an optimal control based EMS is developed and implemented to control the engine on/off status. While implementing the strategy, all the important consideration like aerodynamic drag, vehicle glider mass, accessory loads, prescribed SOC level conditions, and so forth are given utmost attention. PMP along with GA and with modified SOC estimation techniques presents promising EMS. Various governing parameters of vehicle are firstly optimized using GA and then a power

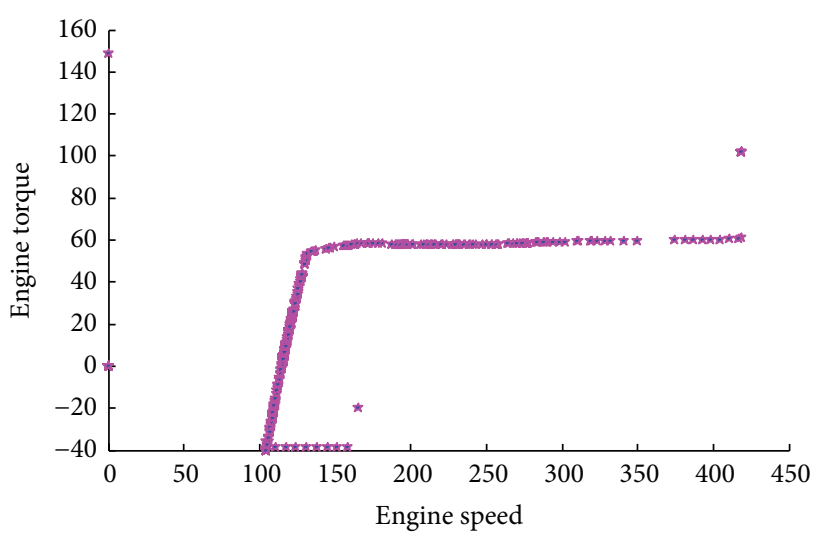

* Efficiency points

(a)

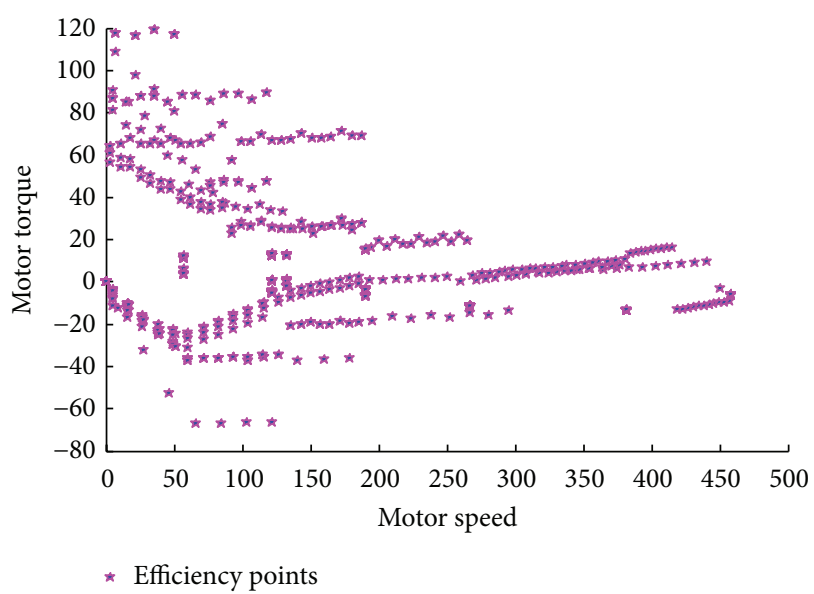

(b)

FIGURE 13: Operating points: (a) engine and (b) motor.

threshold calculation is performed using PMP. Calculation of thresholds initially using GA gives better chance to improve the fuel efficiency. Here, fuel efficiency is derived for different battery models incorporating modified and conventional SOC estimation methods. This proposed EMS yields better efficiency as compared to the default strategy available.

\section{Conflict of Interests}

The authors declare that they have no conflict of interests.

\section{References}

[1] G. J. Jos, G. J.-M. Olivier, and A. H. W. Jeroen, Trends in Global $\mathrm{CO}_{2}$ Emissions, $\mathrm{PBL}$ Netherlands Environmental Assessment Agency, 2012.

[2] L. Schipper, H. Fabian, and J. Leather, "Transport and carbon dioxide emissions: forecasts, options analysis, and evaluation," Working Paper 9, Asian Development Bank, 2009.

[3] Japan Automobile Manufacturers Association Inc, Reducing $\mathrm{CO}_{2}$ Emissions in the Global Road Transport Sector, Japan Automobile Manufacturers Association Inc, 2008. 
[4] M. Ehsani, Y. Gao, and A. Emadi, Modern Electric, Hybrid Electric, and Fuel Cell Vehicles-Fundamentals, Theory and Design, chapter 2-9, CRC Press, New York, NY, USA, 2010.

[5] V. H. Johnson, K. B. Wipke, and D. J. Rausen, "HEV control strategy for real-time optimization of fuel economy and emissions," Society Automotive Engineers, vol. 109, no. 3, pp. 1677$1690,2000$.

[6] G. Paganelli, G. Ercole, A. Brahma, Y. Guezennec, and G. Rizzoni, "General supervisory control policy for the energy optimization of charge-sustaining hybrid electric vehicles," Society Automotive Engineers Review, vol. 22, no. 4, pp. 511-518, 2001.

[7] G. Paganelli, M. Tateno, A. Brahma, G. Rizzoni, and Y. Guezennec, "Control development for a hybrid-electric sportutility vehicle: strategy, implementation, and test results," in Proceedings of the American Control Conference, pp. 5064-5069, Arlington, Va, USA, June 2001.

[8] A. Sciarretta, M. Back, and L. Guzzella, "Optimal control of parallel hybrid electric vehicles," IEEE Transactions on Control Systems Technology, vol. 12, no. 3, pp. 352-363, 2004.

[9] M. Debert, G. Colin, Y. Chamaillard, L. Guzzella, A. KetfiCherif, and B. Bellicaud, "Predictive energy management for hybrid electric vehicles-prediction horizon and battery capacity sensitivity," in Proceedings of the 6th IFAC Symposium Advances in Automotive Control (AAC '10), pp. 270-275, July 2010.

[10] R. Beck, F. Richert, A. Bollig et al., "Model predictive control of a parallel hybrid vehicle drivetrain," in Proceedings of the 44th IEEE Conference on Decision and Control, and the European Control Conference (CDC-ECC '05), pp. 2670-2675, IEEE, December 2005.

[11] I. Arsie, M. Graziosi, C. Pianese, G. Rizzo, and M. Sorrentino, "Optimization of supervisory control strategy for parallel hybrid vehicle with provisional load estimate," in Proceedings of the 7th International Symposium on Advanced Vehicle Control (AVEC '04), pp. 483-488, Arnhem, The Netherlands, August 2004.

[12] D. Prokhorov, “Toyota prius HEV neurocontrol," in Proceedings of the International Joint Conference on Neural Networks (IJCNN '07), pp. 2129-2134, IEEE, Orlando, Fla, USA, August 2007.

[13] M. Huang and H. Yu, "Optimal multilevel hierarchical control strategy for parallel hybrid electric vehicle," in Proceedings of the IEEE Conference Vehicle Power and Propulsion (VPPC '06), pp. 1-4, Windsor, UK, September 2006.

[14] M. Huang and H. Yu, "Optimal control strategy based on PSO for powertrain of parallel hybrid electric vehicle," in Proceedings of the IEEE International Conference on Vehicular Electronics and Safety (ICVES '06), pp. 352-355, IEEE, Beijing, China, December 2006.

[15] Z. Wang, B. Huang, W. Li, and Y. Xu, "Particle swarm optimization for operational parameters of series hybrid electric vehicle," in Proceedings of the IEEE International Conference Robotics and Biomimetics, pp. 682-688, Kunming, China, December 2006.

[16] L. Serrao and G. Rizzoni, "Optimal control of power split for a hybrid electric refuse vehicle," in Proceedings of the American Control Conference (ACC '08), pp. 4498-4503, Seattle, Wash, USA, June 2008.

[17] N. Kim, D. Lee, W. Cha S, and H. Peng, "Optimal control of a plug-in hybrid electric vehicle (PHEV) based on driving patterns," in Proceedings of the International Battery, Hybrid and Fuel Cell Electric Vehicle Symposium, pp. 1-9, Stavanger, Norway, May 2009.
[18] S. Stockar, V. Marano, G. Rizzoni, and L. Guzzella, "Optimal control for plug-in hybrid electric vehicle applications," in Proceedings of the American Control Conference (ACC '10), pp. 5024-5030, Baltimore, Md, USA, July 2010.

[19] S. Stockar, V. Marano, M. Canova, G. Rizzoni, and L. Guzzella, "Energy-optimal control of plug-in hybrid electric vehicles for real-world driving cycles," IEEE Transactions on Vehicular Technology, vol. 60, no. 7, pp. 2949-2962, 2011.

[20] N. Kim, A. Rousseau, and D. Lee, "A jump condition of PMPbased control for PHEVs," Journal of Power Sources, vol. 196, no. 23, pp. 10380-10386, 2011.

[21] N. Kim, S. W. Cha, and H. Peng, "Optimal equivalent fuel consumption for hybrid electric vehicles," IEEE Transactions on Control Systems Technology, vol. 20, no. 3, pp. 817-825, 2012.

[22] K. B. Wipke, M. R. Cuddy, and S. D. Burch, "ADVISOR 2.1: a user-friendly advanced powertrain simulation using a combined backward/forward approach," IEEE Transactions on Vehicular Technology, vol. 48, no. 6, pp. 1751-1761, 1999.

[23] A. Piccolo, L. Ippolito, V. Galdi, and A. Vaccaro, "Optimisation of energy flow management in hybrid electric vehicles via genetic algorithms," in Proceedings of the IEEE/ASME International Conference on Advanced Intelligent Mechatronics, vol. 1, pp. 434-439, Como, Italy, July 2001.

[24] A. Wang and W. Yang, "Design of energy management strategy in hybrid electric vehicles by evolutionary fuzzy system Part II: tuning fuzzy controller by genetic algorithms," in Proceedings of the 6th World Congress on Intelligent Control and Automation (WCICA '06), pp. 8324-8328, Dalian, China, 2006.

[25] B. Huang, X. Shi, and Y. Xu, "Parameter optimization of power control strategy for series hybrid electric vehicle," in Proceedings of the IEEE Congress on Evolutionary Computation (CEC '06), pp. 1989-1994, Vancouver, Canada, July 2006.

[26] R. S. Wimalendra, L. Udawatta, E. M. C. P. Edirisinghe, and S. Karunarathna, "Determination of maximum possible fuel economy of HEV for known drive cycle: genetic algorithm based approach," in Proceedings of the 4th International Conference on Information and Automation for Sustainability (ICIAFS '08), pp. 289-294, IEEE, Colombo, Sri Lanka, December 2008.

[27] X. Tang, X. Mao, J. Lin, and B. Koch, "Li-ion battery parameter estimation for state of charge," in Proceedings of the IEEE American Control Conference (ACC '11), pp. 941-946, IEEE, July 2011.

[28] M. Verbrugge and E. Tate, "Adaptive state of charge algorithm for nickel metal hydride batteries including hysteresis phenomena," Journal of Power Sources, vol. 126, no. 1-2, pp. 236-249, 2004.

[29] A. Panday and H. O. Bansal, "Temperature dependent circuitbased modeling of high power Li-ion battery for plug-in hybrid electrical vehicles," in Proceedings of the International Conference on Advances in Technology and Engineering (ICATE '13), pp. 1-6, IEEE, Mumbai, India, January 2013.

[30] A. Panday and H. O. Bansal, "Hybrid electric vehicle performance analysis under various temperature conditions," Energy Procedia, vol. 75, pp. 1962-1967, 2015.

[31] A. Panday, H. O. Bansal, and P. Srinivasan, “Thermoelectric modeling and online SOC estimation of Li-ion battery for plug-in hybrid electric vehicles," Modelling and Simulation in Engineering, vol. 2016, Article ID 2353521, 12 pages, 2016.

[32] E. Cliffs, Electrochemical Systems, Prentice-Hall, 2nd edition, 1991. 
[33] B. E. Conway, “Transition from 'Supercapacitor' to 'Battery' behavior in electrochemical energy storage," Journal of the Electrochemical Society, vol. 138, no. 6, pp. 1539-1548, 1991.

[34] M. Chen and G. A. Rincón-Mora, "Accurate electrical battery model capable of predicting runtime and I-V performance," IEEE Transactions on Energy Conversion, vol. 21, no. 2, pp. 504511, 2006.

[35] J. Liu, H. Peng, and Z. Filipi, "Modeling and analysis of the Toyota hybrid system," in Proceedings of the IEEE/ASME International Conference on Advanced Intelligent Mechatronics, pp. 134-139, IEEE, Monterey, Calif, USA, July 2005.

[36] C. Mi, M. A. Masrur, and D. W. Gao, Hybrid Electric Vehicles, Principles and Applications with Practical Perspective, John Wiley \& Sons, London, UK, 2011.

[37] S. Sumathi and P. Surekha, Computational Intelligence Paradigm, Theory and Application Using MATLAB, chapter 13, CRC Press, New York, NY, USA, 2010.

[38] K. Deb, "Practical optimization using evolutionary methods," KanGAL Report 2005008, 2005.

[39] V. F. Krotov, Global Methods in Optimal Control Theory, Marcel Dekker, New York, NY, USA, 1996. 


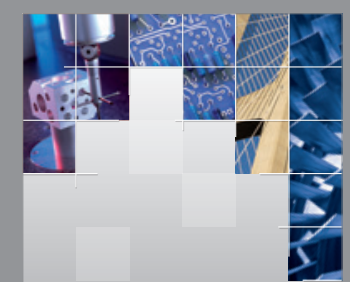

\section{Enfincering}
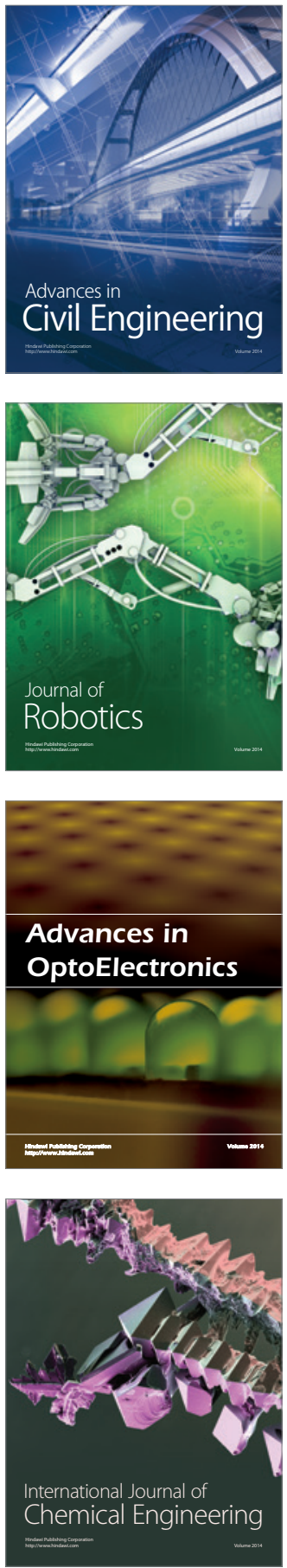

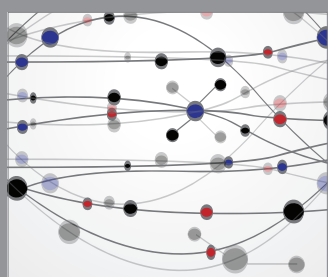

The Scientific World Journal

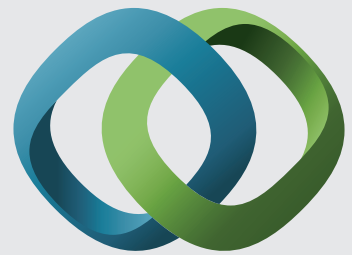

\section{Hindawi}

Submit your manuscripts at

http://www.hindawi.com
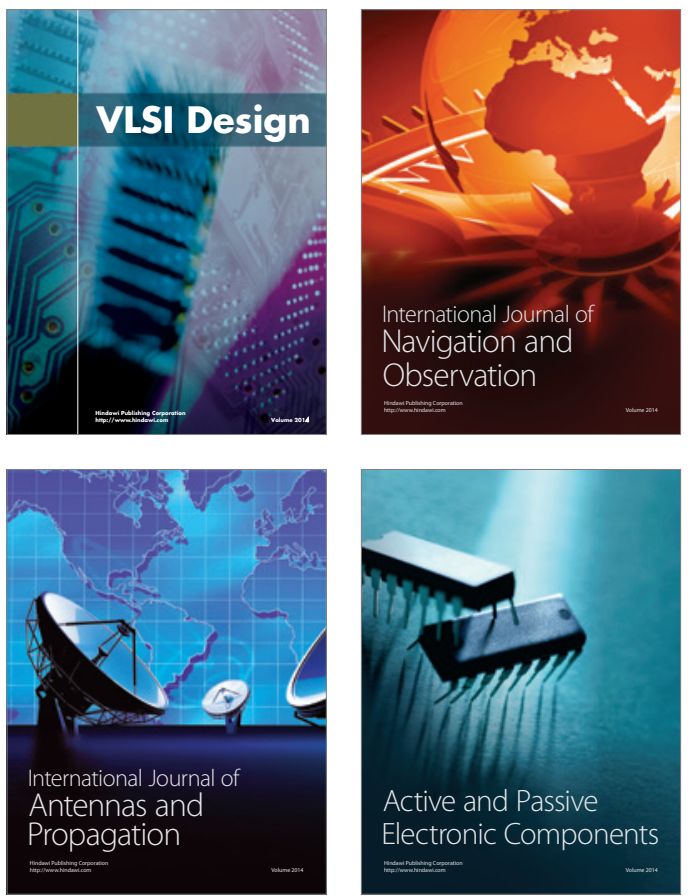
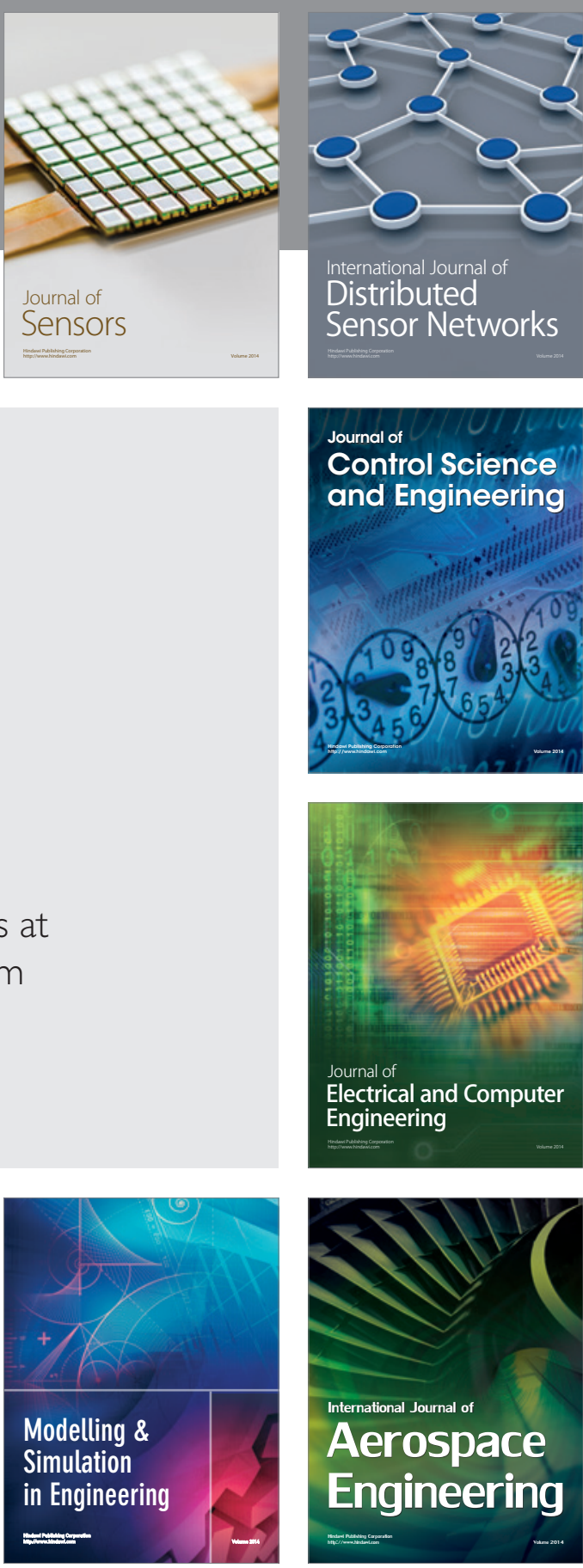

International Journal of

Distributed

Sensor Networks

Journal of

Control Science

and Engineering
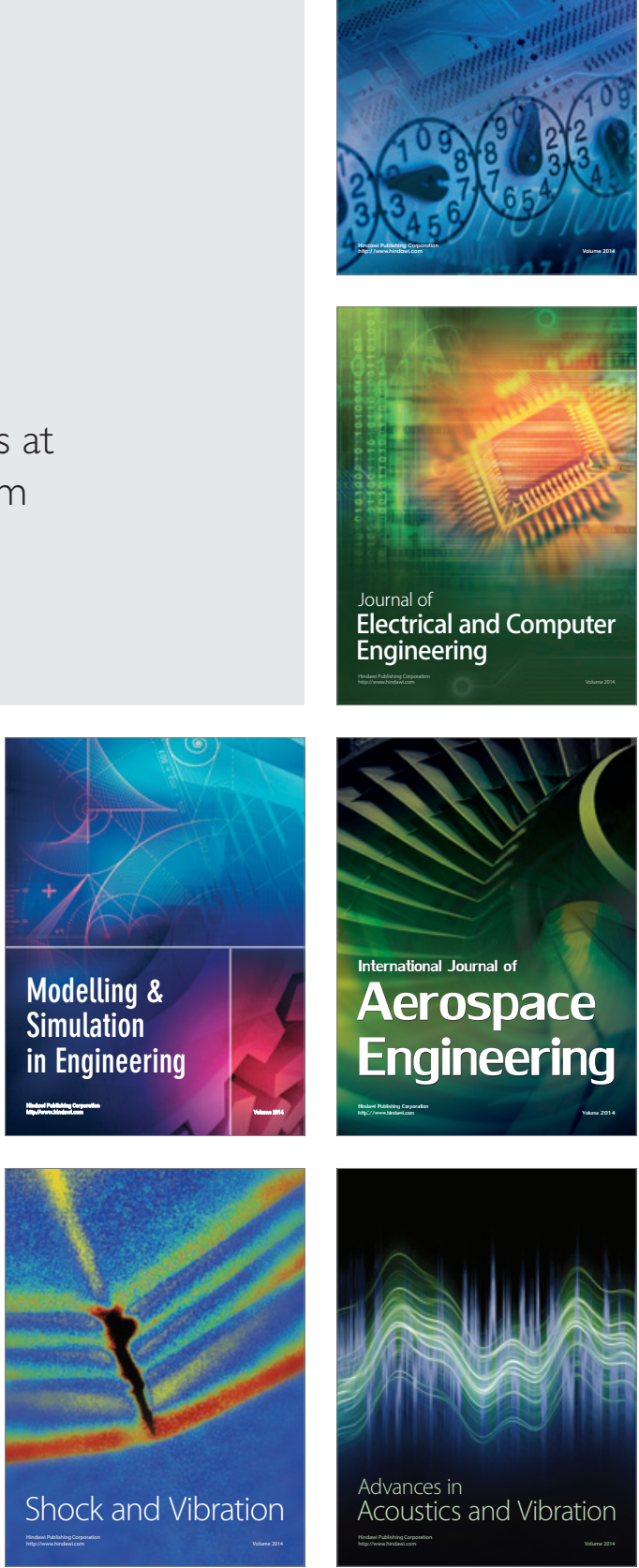